\title{
EVIDÊNCIAS DA EVOLUÇÃO DOS SISTEMAS DE PALEODRENAGENS NA PLATAFORMA CONTINENTAL DA REGIÃO DE SÃO SEBASTIÃO (LITORAL NORTE DO ESTADO DE SÃO PAULO)
}

\author{
Luis Américo Conti \\ Escola de Artes Ciências e Humanidades - EACH. Universidade de São Paulo - Av. Arlindo Bettio, 1000 - Ermelino \\ Matarazzo Cidade - São Paulo - SP - Cep 03828-000
}

\begin{abstract}
Resumo
Este trabalho apresenta aspectos da relação entre a evolução da paleodrenagem e evolução do nível do mar pós Ultimo Máximo Glacial (UMG) para a região da plataforma continental da região de São Sebastião, Litoral norte do Estado de São Paulo - Brasil. Para tal, foram analisados modelos topográficos de detalhe da região de Plataforma Continental a partir de Modelos Digitais de Terreno além de dados de subsuperfície obtidos a partir de linhas sísmicas de alta resolução. Dois grandes sistemas de paleodrenagens foram identificados e descritos para a área. Ambos os sistemas fluviais apresentam boas evidencias de preservação tanto em topografia de fundo (ainda que recoberto por sedimentos transgressivos marinhos) quanto em subsuperfície, associado a feições de corte e preenchimento (escavação de superfície regressiva erosiva). O conjunto de evidencias do estabelecimento de paleodrenagens foi denominado neste trabalho como Sistemas Canal/Vale (SCV). No caso da região estudada, é possível observar que os registros dos SCVs apresentam dimensões consideravelmente grandes (tamanho dos vales/canais) em relação à atual rede de drenagem costeira na área. Modelos descritos na literatura sugerem que rápidas transgressões marinhas tendem a amplificar o efeito erosivo da passagem da linha de costa e afogamento dos canais o que poderia explicar a incongruência entre as características dos sistemas hidrológicos atuais e os registros geológicos e geomorfológicos, sugerindo que os processos de subida do nível do mar pós UMG deve ter sido rápido o suficiente, na região estudada para que pequenos canais fluviais (como o Rio Juqueriquerê) tenham sido fortemente erodidos, formando feições como vales e canais escavados de dimensões consideráveis
\end{abstract}

Palavras-chave: Plataforma Continental, Modelos Digitais de Terreno, Sistemas Canal/Vale, São Sebastião.

\begin{abstract}
The evolution of paleo incised-valleys on São Sebastião Region - southeasthern Brazilian continental shelf - in relation with the post Last Glacial Maximum - LGM sea-level rises is presented in this work, based on the submarine topography modeled by a detailed Digital Elevation Model and evidences noted in high resolution seismic profile; two large paleo valleys were identified and described in the area. Both systems have very clear registers in sea bed topography (even covered by transgressive marine sediments) and also associated to cut/fill features in subsurface (i.e. incised channels in the regressive erosive surface). The set of evidences of these paleo drainages was denominated "Channel/Valleys" Systems (CVS). The dimensions of the CVS in the area are quite large in relation to the size of the fluvial basin and the modern drainage network in the area. Models described in the literature sustain that faster marine transgressions trend to increase the erosional potential in river mouths during drowning processes what can explain this incongruence between the characteristics of the original hydrological network and the geological and geomorfological register, what may suggests that the marine transgression after LGM was fast enough to erode small rivers estuaries (such as Juqueriquerê River) producing large geomorfological registers such as deep valleys and clear erosional channels.
\end{abstract}

Keywords: Continental Shelf; Digital Terrain Model; Paleo-Valley; São Sebastião 


\section{Introdução}

Feições geomorfológicas associadas à presença de canais fluviais em plataformas continentais podem ser indicativas de uma série de processos relacionados a mudanças ambientais e variações do nível do mar durante o Quaternário. Na maior parte dos casos, além da dinâmica sedimentar envolvida em eventos de transferência do nível de base que mudam o regime de aporte (provocando eventuais deslocamentos de leitos), eventos tectônicos podem exercer um papel preponderante neste tipo de regime migratório, podendo estabelecer barreiras para o fluxo forçando a migração de canal, ou ao contrário, encaixando o canal em um curso fixo. Estudos recentes revelam que a presença e geometria de paleodrenagens em plataforma continental e posição das drenagens atuais podem não apresentar uma relação direta, culminando em uma série de questões não totalmente resolvidas para o estabelecimento de um modelo de relação entre a rede de drenagem, regime hidrológico e evolução de feições morfológicas em plataforma continental (Lobo et al, 2006, Abreu e Cagliari, 2005, Ciocci 2001, Lericolais et al., 2001, Popescu et al. 2001 e Winguth et al, 2000 Ciocci et al. 1997).

Uma questão relevante no que se refere à origem e evolução de paleodrenagens, refere-se à relação entre a nomenclatura, comumente usada indiscriminadamente de "paleocanais" e "paleovales". Em termos geomorfológicos, consideram-se canais como feições escavadas, profundos e largos o suficiente para transportar água e sedimento a ele fornecido, enquanto um vale pode conter mais de um canal e ter uma dimensão e profundidade maior do que uma unidade de canal (Wescott, 1993). Embora esta definição seja estabelecida, para o caso das plataformas continentais, a identificação e análise destes sistemas de (paleo) canais e (paleo) vales torna-se mais problemática, devido ao afogamento, retrabalhamento e recobrimento das estruturas. Considerar-se-á, neste trabalho, o termo paleocanal como referente às estruturas de corte e preenchimento da superfície erosiva, ocorrentes em subsuperfície e identificadas em perfis sísmicos e paleovales, os sistemas identificados a partir da modelagem da topografia do substrato. O termo paleovale, no caso, engloba tanto as feições geomorfológicas de estabelecimento de um ou mais canais, como também os sedimentos estuarinos transgressivos posteriormente depositados, desde que se configurem como uma depressão orientada em uma direção. É de se esperar que, na maior parte dos casos, seja possível identificar ambas as feições (paleocanais e paleovales) associadas. Neste caso, é proposta a nomenclatura "Sistemas Canal/Vale" ou SCV para a descrição do conjunto de feições de superfície e subsuperfície, que identificam processos de escavação fluvial e sua posterior remobilização e preservação.
Outra questão envolve a gênese e posterior reativação de sistemas $S C V$ em diferentes ciclos regressivos/ transgressivos. Diversos trabalhos apontam que, de maneira geral, sistemas fluviais tendem a ocupar a mesma posição longitudinal em plataforma continental em ciclos distintos, escavando canais em diferentes superfícies erosivas sucessivas. Tal fato corrobora a visão de que processos de ascensão do nível do mar podem preservar estruturas gemorfológicas, apesar da passagem da linha de costa e consequente, intensa ação destrutiva. Mais recentemente, alguns estudos mostraram, também, que o papel da diferenciação sedimentar entre os depósitos de canais preenchidos (por sedimentos tipicamente estuarinos e lagunares) também podem influir na compactação dos depósitos marinhos posteriormente depositados, provocando uma subsidência mais intensa e, em consequência, uma possibilidade de re-ativação das drenagens em tais posições (Day \& Giosaan, 2008).

Este trabalho propôs um estudo de caso ao longo da plataforma continental do estado de são Paulo, mais especificamente na região de São Sebastião, em que foram abordadas: morfologia da plataforma continental da área, a partir de modelagem digital de terreno, análises de subsuperfície, a partir de uma série de perfis sísmicos de alta resolução e aspectos da área emersa, a partir de estudo de imagens de satélite. Pretendeu-se, com isso o estabelecimento de algumas questões envolvendo a presença e evolução de paleodrenagens em uma plataforma continental típica de margem continental passiva.

\section{Caracterização da área de estudo.}

A área de estudo encontra-se na região central da Plataforma continental do Estado de São Paulo, junto ao município de São Sebastião. Geomorfologicamente, tal área faz parte do compartimento do "Embaimento de São Paulo", feição condicionada pela região do Cabo de Santa Marta (SC) ao sul e Cabo Frio (RJ) ao Norte. Ressalta-se a importância estratégica da área em vista das recentes descobertas de reservas de grandes dimensões de hidrocarbonetos na bacia de Santos. A localização da área é apresentada na figura 1.

De maneira geral, as características geológicas e geomorfológicas da região da Plataforma Continental foram condicionadas, principalmente, por dois eventos distintos: o processo tectônico Mesozóico-Cenozóico, ligado à reativação do escudo Sul Americano, responsável pelos falhamentos que condicionaram toda a escarpa da Serra do Mar e a sedimentação decorrente das sucessivas transgressões e regressões marinhas quaternárias, responsáveis pela maior parte da distribuição sedimentar do litoral. 


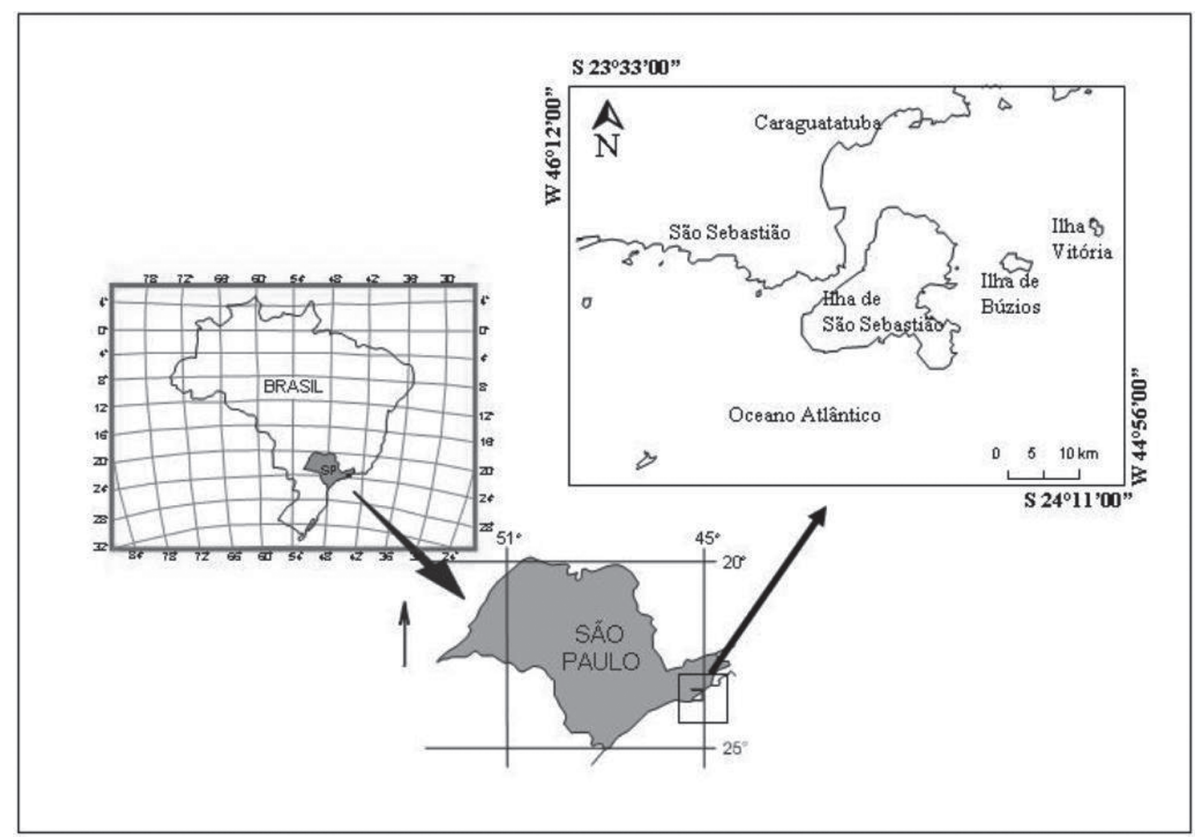

Figura 1 - Localização da área de estudo

O arcabouço geológico está ligado aos processos de desenvolvimento de margens continentais do tipo Atlântico. Almeida (1976) sugere que a evolução tectônica está ligada, primariamente, a possíveis fenômenos termais, que ocorreram a partir do Jurássico Superior, ligados a abertura do Oceano Atlântico. Com a evolução do processo desenvolveramse sistemas de falhamentos a oeste da Bacia que são considerados, pelo autor, como responsáveis pela subsidência da mesma. Decorrente do processo ocorre, também, o soerguimento da Serra do Mar "ancestral", posicionada próxima a Falha de Santos. O maciço rochoso sofreu, então, processos erosivos retrocedendo até a sua posição atual. Esses fenômenos são, segundo o autor, responsáveis pelo suprimento sedimentar para a Bacia de Santos. Grande atividade tectônica ocorreu na região do Cretáceo Superior ao Paleoceno, estando associado a ela intenso vulcanismo alcalino responsável, por exemplo, pela estrutura da Ilha de São Sebastião. As rochas derivadas do vulcanismo alcalino na área foram datadas por Amaral et al. (1966), que obtiveram idades entre 60 a 90 milhões de anos.

A área costeira e a plataforma continental também foram modeladas, durante o Quaternário, por eventos transgressivos e regressivos (Kowsmann et al., 1977; Suguio e Martin, 1978) e, ainda, por eventos de sedimentação associados à circulação geostrófica e termohalina (Mahiques et al., 2007)

Trabalhos como os de Mahiques et al. (2002 e 2007) e Conti (2007) indicam que a região da plataforma continental da região de São Sebastião delimita dois domínios distintos de sedimentação; ao norte, encontram-se sedimentos francamente arenosos depositados em ambientes costeiros regres- sivos e remobilizados por ação marinha, enquanto ao sul, ocorrem faixas de deposição de lamas cuja fonte está associada, possivelmente, a sedimentos argilosos oriundos do estuário do Rio da Prata, ou ainda, em outra interpretação, ao afloramento de lamas transgressivas, depositadas in situ em condições fluvio-lagunares em situação de nível do mar abaixo do atual.

A região emersa adjacente à Plataforma continental é dominada pela Bacia do Rio Juqueriquerê, que em sua porção estuarina é formado por dois rios: o Camburiú e o Claro que se confluem na região da planície costeira de Caraguatatuba. Tem sua nascente na serra homônima, constituída essencialmente por rochas do embasamento cristalino, de idade Pré Cambriana. Ocorrem, também, importantes enxames de diques do Jurássico Superior e Cretáceo inferior (Campanha \& Ens, 1996), que condicionam a morfologia do rio nas porções mais proximais. A região de Caraguatatuba, correspondente a porção costeira da bacia de captação do Rio Juqueriquerê, apresenta uma das maiores regiões de recuo erosivo da serra do mar no litoral norte, possibilitando o estabelecimento de uma planície costeira

O rio Juqueriquerê percorre tal planície recebendo pequenos tributários em por uma distância de, aproximadamente, 27 quilômetros da base do sistema serra do mar até a região costeira. A dimensão da bacia foi calculada a partir da imagem de satélite e apresenta uma área de aproximadamente $850 \mathrm{~km}^{2}$. Trabalhos anteriores reconheceram a presença de paleodrenagens na região estudada (ver Furtado et al. 1995, Conti \& Furtado 2007 e Kowsman e Costa 1976), embora sendo pouco relacionadas diretamente com processos eustáticos (Figura 2). 


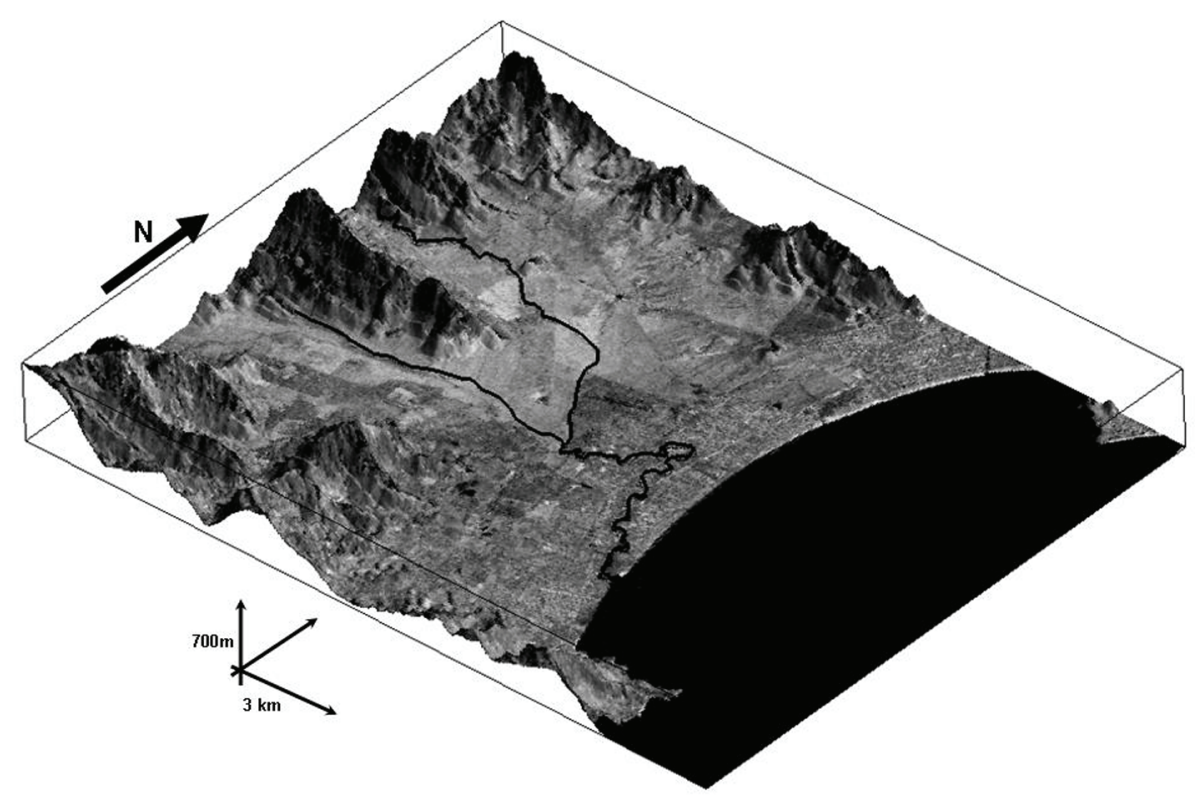

Figura 2 - Imagem de Satélite (Landsat ETM + Pan) em representação 3D com associação dos dados de topografia da região da Planície costeira de Caraguatatuba. A Linha destacada indica a posição do Rio Juqueriquerê.

\section{Métodos}

A topografia da região da plataforma continental foi processada, digitalmente, a partir da elaboração de um Modelo Digital de Terreno (MDT). 65.296 Pontos cotados oriundos da folhas de bordo geradas pela Diretoria de Hidrografia e Navegação da Marinha do Brasil foram digitalizadas a partir dos quais foi gerada uma grade regular para a área com células com dimensões de 100 x 100 metros.

Considerando-se, deste modo, um MDT como uma superfície digital foi possível a extração de uma série de atributos topográficos chamados de superfícies derivadas (derivatives surfaces) dentre as quais destacam-se : declividade, aspecto, curvatura além de uma superfície de tendência polinomial (detalhes do procedimento matemático pode ser encontrado em Pike, 1998). Foi possivel, tambem, a partir da manipulação matemática das células do MDT, a geração de fluxos de drenagem. Esta técnica permite a extração de sentido de fluxo a partir da posição altimétrica de cada célula em relação a direção do maior declive às suas células vizinhas. Quando a direção é encontrada, a célula de output é codificada com o valor que representa essa direção, este valor é dado por uma convenção. O método utilizado foi o SFD-D8 (Single flow direction - deterministic 8 node), em que são utilizados as 8 células diretamente anexas à célula a ser determinada (O'Callaghan \& Mark, 1984; Gallant \& Wilson, 2000). Este processo é extremamente complexo em regiões de plataformas continentais, já que, ao contrário de áreas emersas, o processo gerador das feições, não mais se fazem presentes. Os registros de antigos vales formados em períodos de regressão marinha e escavação sub-aérea, apresentam, na maior parte dos casos, formas irregulares e descontínuas deviduo ao posterior retrabalhamento (e/ou preenchimento) decorrente de processos marinhos subsequentes. Deste modo, para a aplicação de algorítimos geradores de drenagem, comumente encontrados em programas de MDTs, é necessário uma série de procedimentos preliminares, entre os quais destacam-se a aplicação de filtros do tipo "passa alta" (ou realces) que ressaltam estruturas de maiores dimensões e permitem a identificação das maiores faixas de entalhes, e a aplicação de processos de homogenização planar (pit removal) que remove do modelo depressões localizadas que alterariam a continuidade de uma feição de entalhe (Jenson \& Domingues, 1988).

Para a análise das estruturas de sub-superfície, foram analisados uma série de perfis sísmicos obtidos no cruzeiro oceanográfico do Projeto JOPS-1 obtidos com um equipamento Sparker com potência de 1000J, taxa de disparo: 1 pulso/ 1,6 s, freq. 118 $-645 \mathrm{~Hz}$, no ano de $1991 \mathrm{com}$ o N/ Oc. Victor Hensen (convenio Brasil-Alemanha), cobrindo boa parte da região de plataforma interna e média da região de São Sebastião e Ubatuba. Os perfis Sparker, por terem sido adquiridos por um sistema analógico, necessitaram de préprocessamento, ou seja, todos os perfis foram digitalizados e georreferenciados. Trechos de interesse foram realçados e associado a um banco de dados geográfico do projeto.

A relação das áreas emersas adjacentes à plataforma continental em estudo, foram analisadas imagens ETM + (Enhanced Thematic Mapper Plus) do satélite Landsat-7. Foi utilizada a imagem 219/77 adquirida em setembro de $2001 \mathrm{e}$ realizados processamentos e realces, visando destacar estruturas do sistema de drenagem costeira da área alem de feições de interesse na área costeira (material em suspensão e / topografia de fundo). 
Todas as informações obtidas pelo MDT, processamento de imagens de satélite e digitalização e posicionamento das linhas sísmicas, foram armazenadas em um banco de dados geográficos em um Sistema de Informações Geográficas (SIG), tornando possível o acesso, manipulação e associação de todos os dados sobre uma base georreferenciada.

\section{Resultados}

As análises do MDT da plataforma continental mostram que, a partir da atual desembocadura, o Rio Juqueriquerê apresenta duas feições de entalhe na região de plataforma continental, sendo ambos os sistemas de vales condicionados pela presença da Ilha de São Sebastião. (Figura 3)

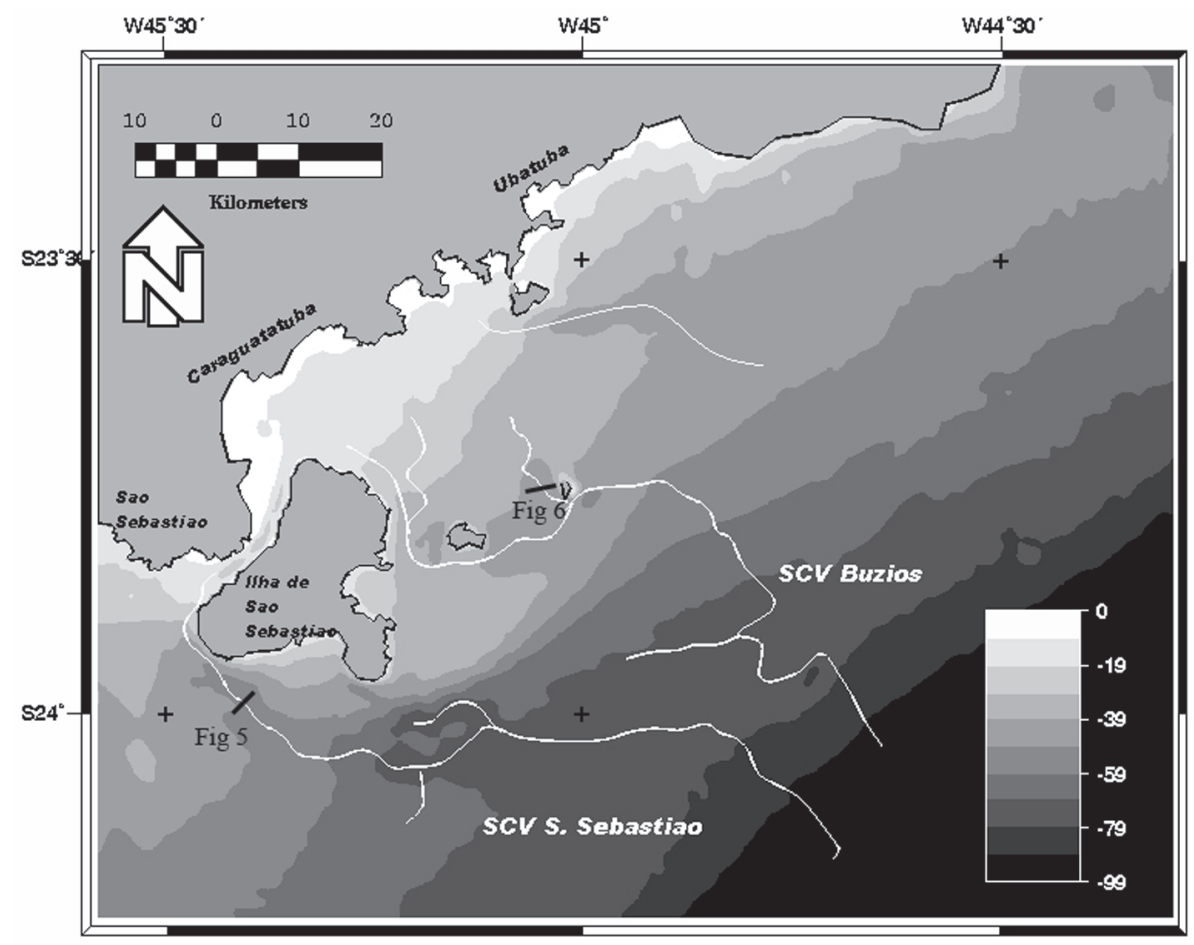

Figura 3 - Posição dos SCV Búzios e São Sebastião, delimitados pela topografia de fundo. Linhas indicam posição dos trechos dos perfis sísmicos mostrados nas figuras 5 e 6

Um primeiro vale aparece na parte NE da Ilha (a ser denominado "SCV Búzios"), seguindo pela plataforma continental passando junto a Ilha de Búzios e apresentando uma inflexão para oeste, outra feição de vale também aparece entre as ilhas de Búzios e Vitória, sendo esta de dimensões menores. Foi possível determinar, a partir de operações de modelagem de terreno, os limites da paleo bacia do sistema, indicando uma condição de boa preservação das características morfológicas da superfície erosiva. Tal característica também é explicada pelo fato desta porção da plataforma ser a menos extensa, com declividade média acentuada em relação à plataforma continental Sul e Norte.

O segundo vale ("SCV São Sebastião") apresenta uma condição muito mais realçada, sendo a diferença de profundidade média entre as margens e o centro de até 12 metros (em contrapartida aos $7 \mathrm{~m}$ do "SCV Búzios", na profundidade aproximada de $60 \mathrm{~m}$ ). Trata-se de uma feição preservada até profundidades superiores a 100 metros. Tal feição conectase à posição atual da desembocadura através do Canal de São Sebastião.
Observando-se o comportamento de ambos os eixos dos vales em relação aos dados de anomalias do relevo (em relação a uma superfície teórica polinomial), foi possível observar que a trajetória do "SCV São Sebastião" é muito mais marcada em termos morfológicos, isso é, apresenta uma área de "influência lateral" mais clara. Enquanto o "SCV Búzios" nota-se tal influência lateral apenas até a isóbata de 50 metros, a partir da qual se posiciona sobre uma superfície quase plana (próxima a tendência) (figura 4).

A partir das análises sísmicas foi possível identificar uma série de estruturas características além de refletores bastante claros o que permitiu tecer considerações referentes a relação entre os paleovales descritos em superfície e as estruturas de subsuperfície da área em questão.

Ao longo de quase toda a série de perfis foi possível a identificação de um refletor raso, que foi associado a uma superfície erosiva devido a suas características de rugosidade, presença de diversas estruturas de corte e preenchimento. Tal refletor apresenta características muito similares ao descrito por Mahiques e Souza (1999) na re- 
gião da Baia do Flamengo em Ubatuba, denominado pelos autores de R1 e interpretados como a superfície associada à exposição subaérea durante o último período regressivo. Este refletor separa duas unidades também bastante características presente em quase todo o registro: na parte superior com espessura variável, aparece uma sequência associada a sedimentos transgressivos denominados "U1". Os padrões de reflexão da unidade U1 variam de plano-paralelos, oblíquos e frequentemente caóticos em associação com algumas estruturas como de corte e preenchimento. Na porção de plataforma média apresenta estruturas do tipo "on lap" em direção ao talude.

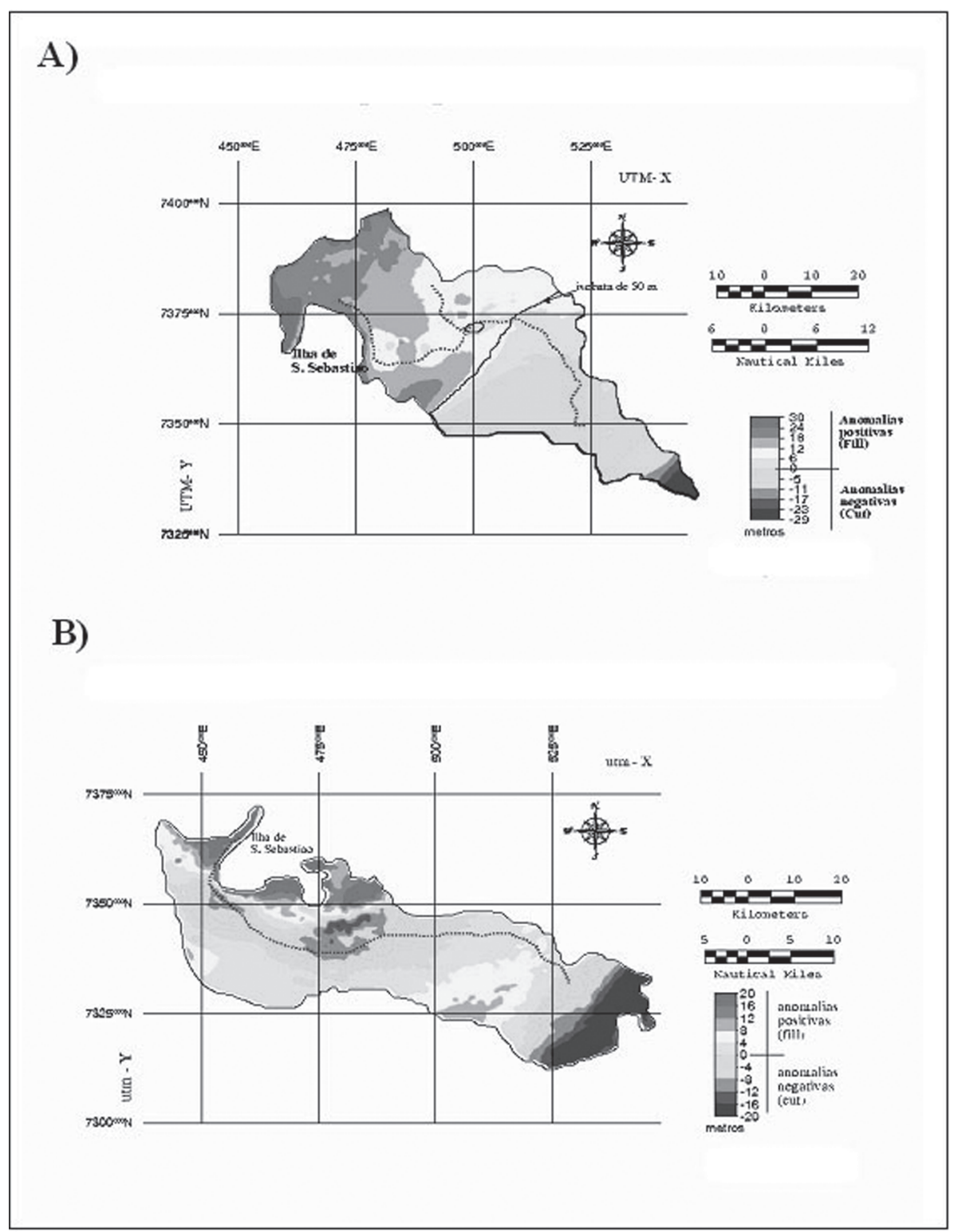

Figura 4 - Posição dos eixos dos paleovales em relação a uma superfície de tendência polinomial da região da plataforma continental. Observa-se que os tons mais frios (verdes e azuis) representam anomalias negativas, ou seja, áreas em que a topografia é rebaixada em relação a tendência.

Abaixo do refletor R1, ocorre uma unidade com espessura variável, com estruturas que, em alguns casos, truncam a superfície R1, denominada U2. Esta unidade apresenta estruturas de reflexão inconstantes e em alguns trechos quase não identificáveis, devido a baixa qualidade dos registros. Em trechos da plataforma média/externa, apresenta padrões de progradação pouco claros em direção ao talude e trunca a unidade U1 em feições de corte e preenchimento.

Quanto ao embasamento acústico (EA), só foi possível observá-lo em 2 perfis, ambos nas partes mais rasas da plataforma continental. Na região adjacente a Ilha de São Sebastião, aparece mais claramente em um tre- 
cho de perfil onde também é possível notar a parte basal da sismo-unidade U2 por um refletor bastante tênue chamado de $\mathrm{R} 2$ e outros refletores ainda menos claros entre R2 e EA.

A relação das estruturas erosivas, principalmente referentes ao refletor R1 apresentaram uma correlação muito boa com as feições de paleovales indicadas no modelo digital de terreno. Pode-se perceber que nas intersecções entre as linhas do registro e as linhas dos eixos de paleovales ocorreram na grande maioria dos casos, feições de corte e preenchimento associadas.
No que se refere aos dois principais sistemas de paleodrenagem ocorrentes na área, esta relação apresentou uma interessante característica: Em locais onde as linhas sísmicas seccionam o canal "SCV São Sebastião", ocorre a presença bastante marcante de estruturas erosivas no refletor R1. Embora os registros não cubram as porções mais exteriores deste canal, pode-se estabelecer claramente a relação entre feições de corte e preenchimento, características de drenagem fluvial e a posição da linha do paleovale (SCV). A Figura 5 Indica um trecho do perfil sísmico associado ao SCV S. Sebastião. É possível observar uma clara feição de corte e preenchimento, típica de escavação fluvial no refletor R1, muito próximo à superfície.

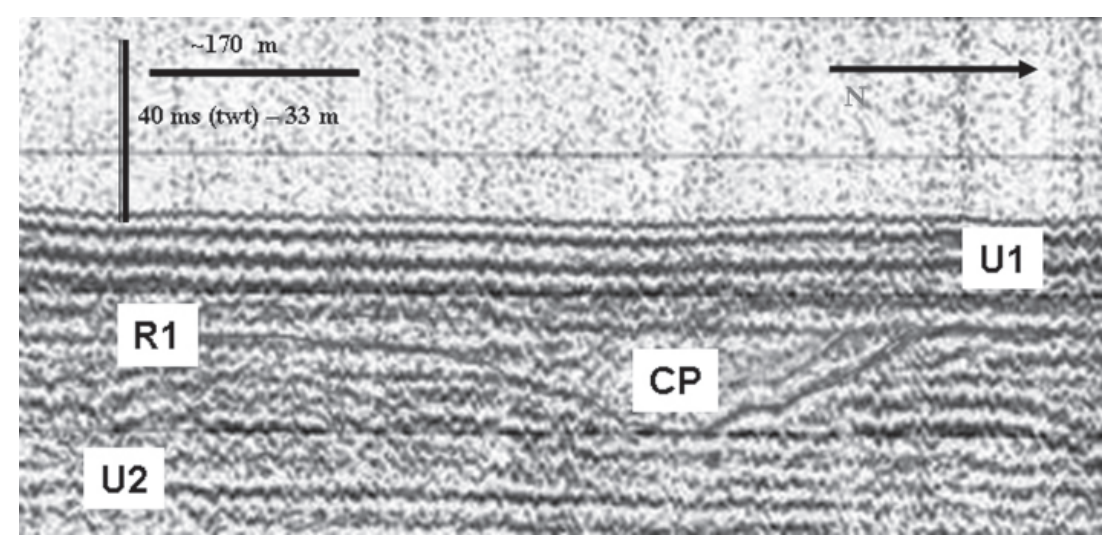

Figura 5 - Trecho do perfil sísmico da região do SCV São Sebastião (como indicado na figura3). $($ R1 = refletor 1 , U1 Sismo unidade 1, U2 = sismo unidade 2, CP - Feição de corte e preenchimento; TWT - Two way time ou tempo de registro da onda sísmica)

O paleovale "Búzios", também apresenta clara relação com feições erosivas de corte e preenchimento, entretanto, tais feições ocorrem, também, em refletores mais profundos, principalmente em R2, o que demonstra que o canal teria escavado uma superfície mais antiga. Nota-se também, que em alguns casos, também há indícios erosivos no refletor R1, o que sugere uma realimentação do sistema fluvial mais antigo em períodos posteriores com dimensões menores. Notase, neste trecho, a presença marcante do embasamento acústico que devido a posição em que se encontra, provavelmente é reflexo de um corpo vulcânico alcalino, cuja natureza é associada à origem do sistema de Ilhas São Sebastião/ Búzios/Vitória.

Pela profundidade aparente do refletor R2 e pela configuração espacial do "SCV Búzios", pode-se supor que este corpo do embasamento deve ter condicionado o curso do rio que escavou tal superfície (Figura 6).

Outra característica a ser observada é o pequeno deslocamento do eixo do paleovale em relação às estruturas de canal identificadas tal qual na maioria dos perfis. Esta diferença de posicionamento pode ser explicada pela natureza não simétrica do canal em relação ao vale e/ou, a acurácia do modelo de terreno gerado

Assim como as análises de sismoestratigrafia puderam elucidar aspectos de formação e evolução dos SCV, estudos mais detalhados envolvendo as regiões internas da plataforma continental podem revelar peculiaridades da correlação dos SCV com a rede de drenagem atual, o que contribui para a compreensão da origem e evolução dos sistemas. Deste modo, para a região da retaguarda da Ilha de São Sebastião, na porção frontal à Enseada de Caraguatatuba, foram gerados modelos mais precisos da batimetria com células de 30 × 30 metros. Nesta escala, percebe-se mais claramente a forma dos dois paleovales em relação á área emersa.

A figura 7 apresenta uma composição da imagem de satélite (em uma composição típica de bandas 3, 2 e1) com o modelo batimétrico. Pode-se observar que mesmo nas áreas mais rasas, é possível identificar os dois paleovales na retaguarda da Ilha de São Sebastião. Identifica-se também, outros dois paleovales a nordeste, que não apresentam continuidade na região de plataforma média. 


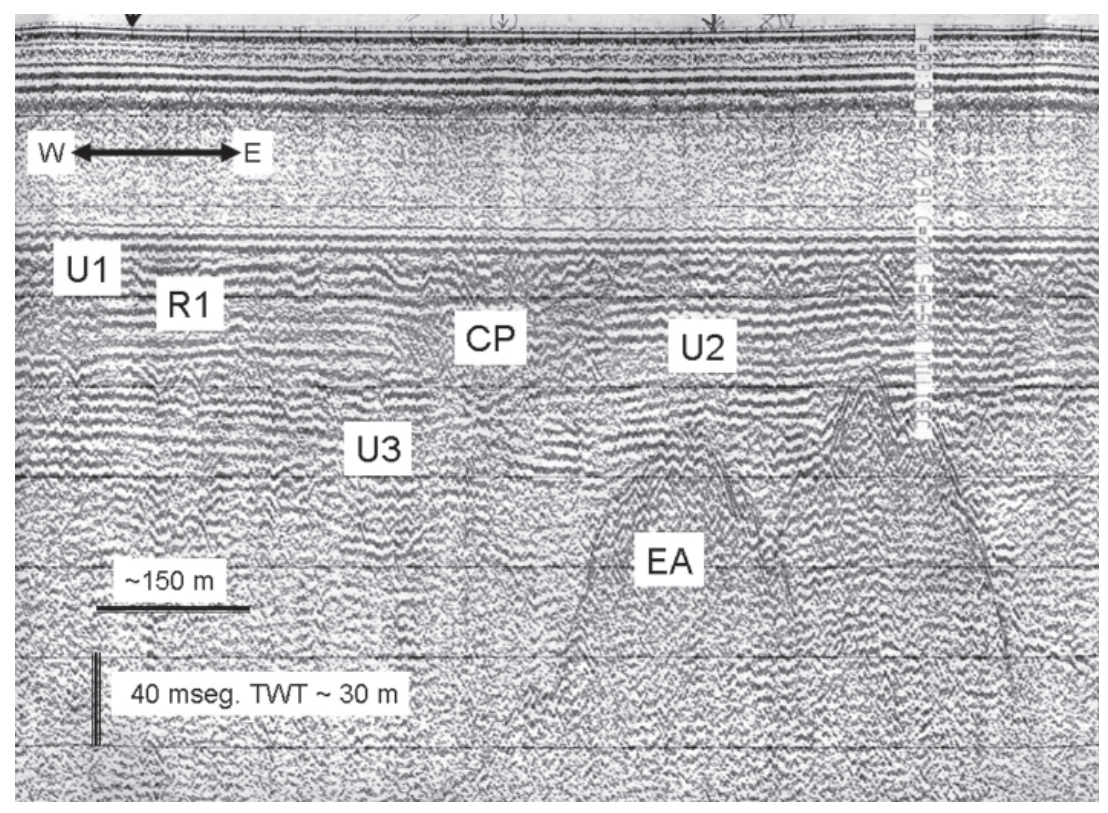

Figura 6 - Trecho do perfil sísmico da região do SCV Búzios (como indicado na figura3). $(R 1=$ refletor 1 , U1 Sismo unidade 1 , U2 = sismo unidade 2, U3= Sismo unidade 3; CP = Feição de corte e preenchimento; EA=Embasamento Acústico; TWT = Two way time ou tempo de registro da onda sísmica)

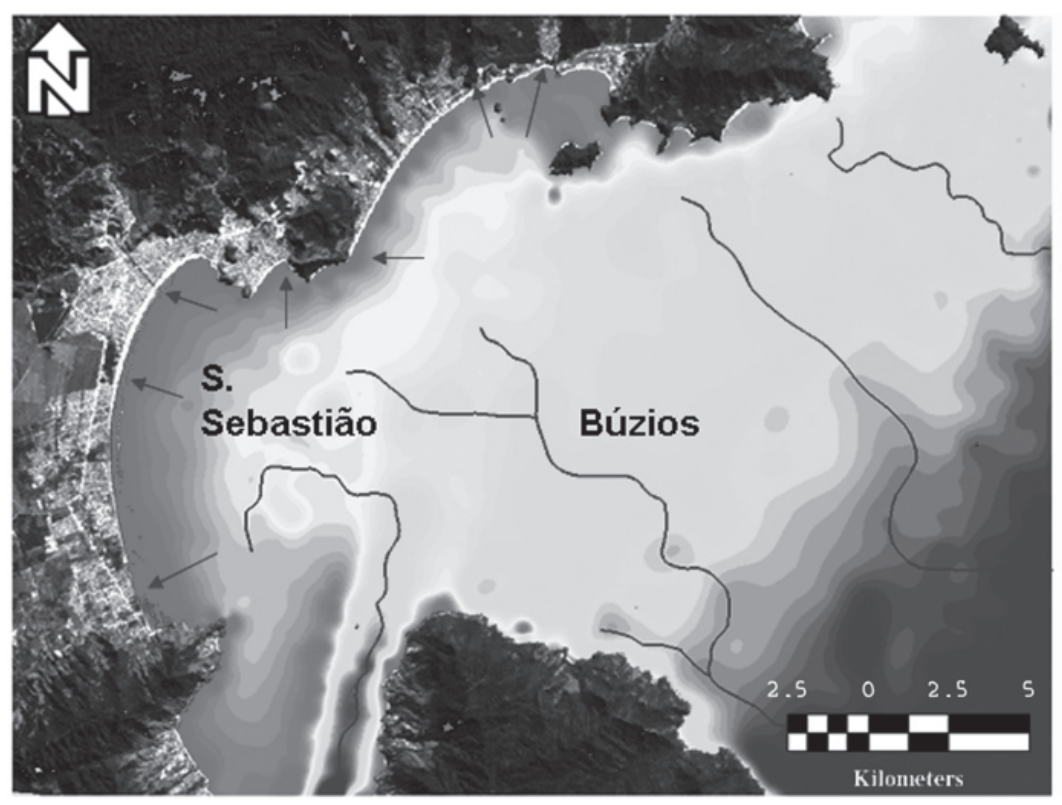

Figura 7 - Associação de um MDT de detalhe em composição com imagem de Satélite Landsat 7 ETM + da área emersa

Devido à configuração do relevo submerso e geometria das drenagens, pode-se supor que os paleovales em plataforma receberam a contribuição de mais rios, além do Juqueriquerê. Uma feição mais rasa com direção aproximada S-N pode ser identificada na parte frontal da enseada de Caraguatatuba e influencia de modo acentuado a remobilização de sedimentos de fundo. Tal feição apresentase como uma continuidade morfológica de um pontal arenoso da parte norte continental do Canal de São Sebastião, estudada por Furtado, (1978) e Conti, (1998), cuja origem está possivelmente associada a um sistema tipo «barreira », com um corpo lagunar a retaguarda. Esta feição claramente deter- 
mina a geometria dos SCV na porção interna da plataforma continental da região a retaguarda da Ilha de São Sebastião.

A partir de programas de computação gráfica e da utilização dos dados referentes a altimetria e batimetria gerados pelo MDT, foi possível, também, gerar imagens sintéticas de simulação da paisagem da região de plataforma continental em período de nível do mar regressivo. Tal técnica pode ser bastante interessante para a vizualização de paleopaisagens
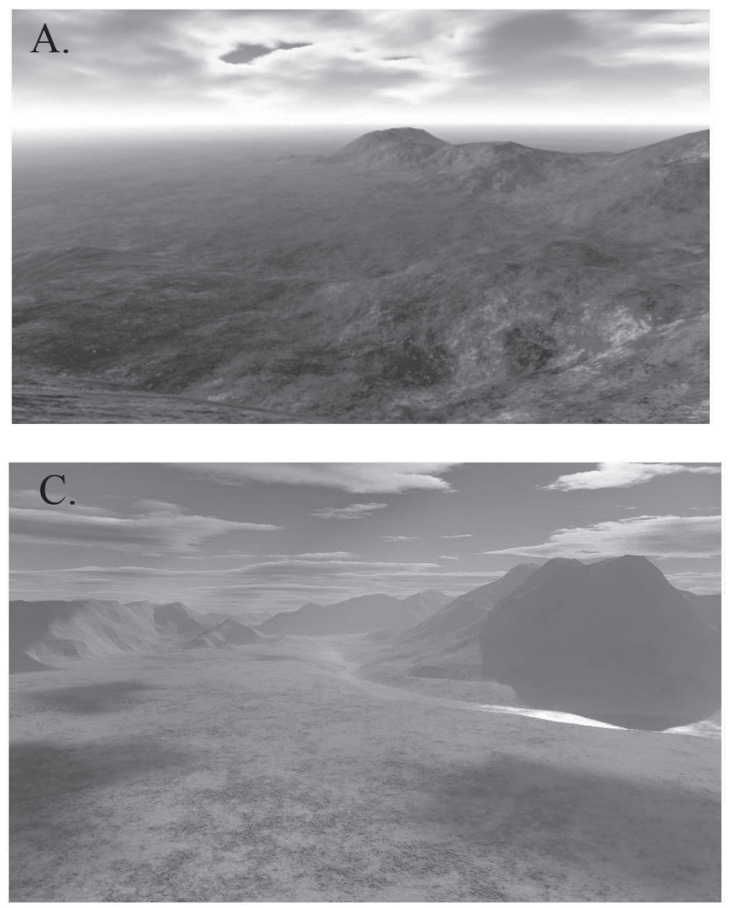

criando elementos como drenagens, textura de vegetação e substrato rochoso alem da modelagem da atmosfera e elementos celestes (posição do sol, lua etc). A figura 8 apresenta uma série de simulações de paisagens da região em estudo sob diversas visadas e pontos de foco. Nota-se que é possível observar a posição dos vales em relação à topografia baseada nos MDTs e na posição das feições encontradas nos perfis sísmicos.
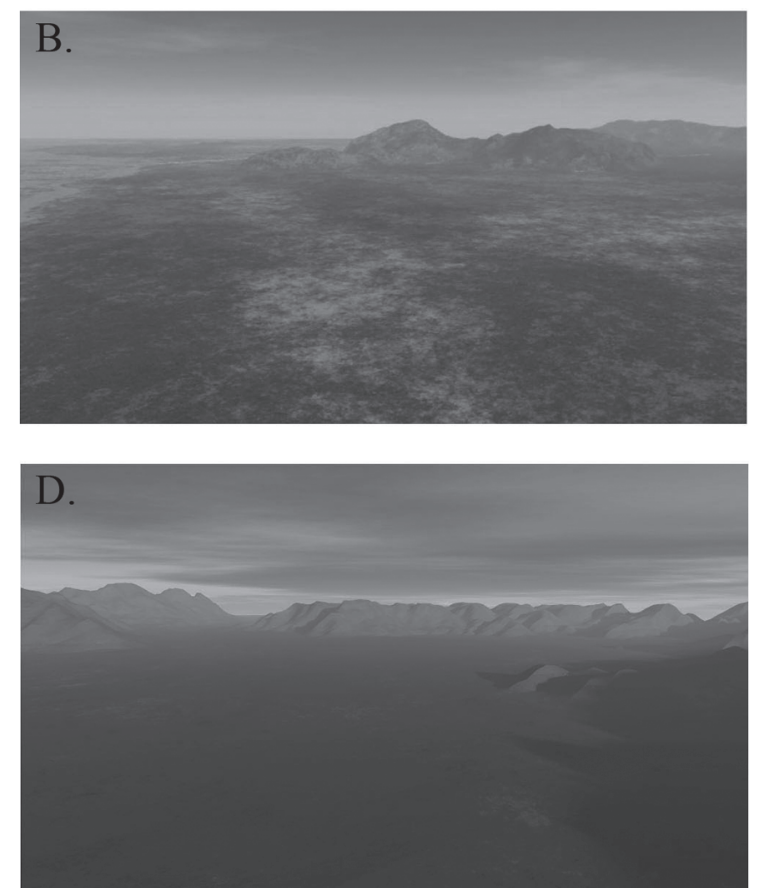

Figura 8 - Técnicas de computação gráfica permitem a simulação de paisagens em períodos de mar abaixo do atual. A) Visada de cima da Ilha de São Sebastião em direção a plataforma continental. B) Visada da Ilha Vitória para a Ilha de São Sebastião. C) Canal de São Sebastião e Rio associado ao SCV S. Sebastião. D) Enseada de Caraguatatuba e Serra do Juqueriquerê.

\section{Discussão e Conclusões}

Atualmente, na região costeira de São Sebastião, devido à proximidade dos contrafortes da serra do mar em relação à posição atual da linha de costa, não há o desenvolvimento de redes de drenagens atuais proeminentes; os maiores rios da área apresentam dimensões reduzidas tanto geometricamente quanto em termos de fluxo, como é o caso do Rio Juqueriquerê. Em uma situação de nível do mar abaixo do que o atual, entretanto, uma extensa planície costeira foi formada, permitindo a captação desse grande número de pequenas drenagens, em sistemas fluviais de maiores dimensões drenando toda a região de plataforma continental.

Os dois sistemas fluviais, de dimensões consideráveis, que se estabeleceram na região em períodos regressivos foram condicionados pelos corpos alcalinos ocorrentes na região determinando a geometria dos cursos. A Ilha de São Sebastião, especificamente, serviu como um anteparo para os 
Em termos topográficos, os dois sistemas são facilmente identificáveis a partir da aplicação de algorítimo de extração de eixos de runoff a partir dos MDTs, sendo o SCV São Sebastião, muito mais marcado, apresentando um vale muito pronunciado junto a desembocadura sul do canal de São Sebastião. Em ambos os sistemas, é possível acompanhar vestígios em topografia até profundidades superiores a 100 metros. Mesmo assumindo o fato de que tais sistemas captariam a carga de uma bacia concideravelmente maior do que a atual bacia do Juqueriquerê, é difícil explicar como feições topográficas tão pronunciadas podem ser preservadas após o processo de elevação do nível do mar, posterior ao Último Máximo Glacial (UMG) e ainda o soterramento por sedimentos marinhos holocênicos.

Koss et al. (1994), a partir de um modelo físico em escala, mostrou que além da posição do nível de base, o regime de escavação de canais e o estabelecimento de paleovales é influenciado, também, pela velocidade da regressão ou transgressão marinha, já que o tempo de estabilização de um perfil de equilíbrio é um fator decisivo para compreensão dos tipos de feições geradas. Segundo o autor, a evolução de sistemas fluviodeltáicos, em regime de variações do nível do mar, pode ser generalizada a partir de um modelo de estágios, baseados no aporte de sedimentos e velocidade dos processos eustáticos. Este modelo, explica, de certo modo, como os SCV poderiam ser preservados no caso de processos de regressão marinha lenta seguida por transgressão rápida (como, provavelmente ocorreu durante o último ciclo glacial). Associado a este processo, alguns trabalhos também apontam a importância de eventos eustáticos de maiores frequências (aproximadamente 1 a 5.000 anos) associados a variações climáticas pós UMG, permitindo uma reativação de processos de incisão de vales em menor escala (Steinke et al., 2003).

\section{Referências Bibliográficas}

Abreu, J.G.N. \& Calliari, L. 2005. Paleocanais na Plataforma Continental Interna do Rio Grande do sul: Evidências de uma drenagem fluvial pretérita. Revista Brasileira de Geofísísica (2005) 23(2): 123-132

Almeida, F.F.M. 1976. The systems of continental rifts bordering the Santos Basin, Brazil. Anais Acad. Bras. Ci. 48 (supl.): 15-26.

Amaral, G.; Cordani, U.G.; Kawashita, K. 1966. PotassiumArgon data of basaltic rocks from Southern Brazil. Geochem. Cosmochem Acta. 31(2):117-142.

Campanha, G.A.C., Ens, H.H., Poncano, W.L. 1994. Analise morfotectonica do Planalto do Juqueriquere. Rev. Bras. Geoc., SBG, Sao Paulo
Chiocci, F. 2001. Continental Shelf morphoestratigraphic features due the last sea level rise : certanities and uncertanitieswith examples of Mediterran shelf. In roceedings of 1 st Annual Conference of "Continental Shelves during the last Glacial Cycle". IGCP Project 464) UNESCO.

Chiocci, F.L., Ercilla G. \& Torres J.1997. Stratal architecture of western Mediterranean margin as the result of the stacking of Quaternary lowstand deposits below "glacio-eustatic fluctuation baselevel". Sedimentary Geology, 112, 195-217

Conti, L.A.; Furtado, V.V. 2006. Geomorfologia da Plataforma Continental do estado de São Paulo. Revista Brasileira de Geociências, v. 32, p. 12-31.

Conti, L.A. 1998. Aplicação de técnicas de geoprocessamento na caracterização de aspectos morfossedimentares do Canal de São Sebastião - Litoral Norte do estado de São Paulo" Dissertação de Mestrado apresentada ao instituto Oceanográfico da Universidade de São Paulo.

Day, J.W. \& Giosaan, L.G. 2008. Survive or subside. Nature Geoscience 1, 156 - 157 (2008)

Furtado, V.V. 1978. Contribuição ao estudo da sedimentação atual no Canal de São Sebastião, Tese de doutorado. Universidade de São Paulo, Inst. de Geociências.

Furtado, V.V.; Bonetti Filho, J. \& Conti L.A. 1995 paleoriver valley morphology and sea level changes at southeastern Brazillian continental shelf. Anais Anais da Acad. Brás. de Ci., v. 68, p. 163-169,

Gallant, J. C. \&. Wilson J. P. 2000. Primary Topographic Attributes. Terrain Analysis: Principles and Applications. J. P. Wilson, Gallant, J. C. New York, John Wiley and Sons: 51-85

Jenson S.K. \& Dominguez J.O. 1988. Extracting topographic structure from digital elevation data for geographic information. Photogramm. Eng. Remote Sensing 54: $1593-1600$

Koss, J. E., Ethridge, F., \& Schumm, S. A. 1994. An experimental study of the effects of base-level change on fluvial, coastal plain and shelf systems: Journal of Sedimentary Research, v. B64, p. 90-98.

Kowsmann, R.O. ; Costa, M.P.A.1978. Evidence of Late Quaternary sea level stillstands on the upper brazilian continental margin: a synthesis. Proceedings of the 1978 International Symposium on Coastal Evolution in the Quaternary. /Instituto de Geociências-USP, S.Paulo, p. 172-192. 
Lericolais, G., Berné, S. \& Fenies, H.. 2001. Seward pinching and internal stratigraphy of the Gironde incised valley on the shelf (Bay of Biscay). Marine Geology. 175 183-179

Lobo, F.J. Fernández-Salas, I. Moreno, J.L. Sanz \& Maldonado, A. 2006. Shallow-water depositional bodies and sediment by-pass styles in a Mediterranean shelf fed by small rivers, northern Alboran Sea margin, Cont. Shelf Res. 26 (2006), pp. 2607-2628

Mahiques, M. M. ; Souza, L. A. P.1999 . Shallow seismic reflectors and upper Quaternary sea level changes in the Ubatuba region, São Paulo State, Southeastern Brazil. Revista Brasileira de Oceanografia, São Paulo, v. 47, n. 1, p. 1-10

Mahiques, M. M. ; Fukumoto, M;M. ; Silveira, I.C.A. ; Figueira, R.C.L. ; Bicego, M.C. ; Lourenço, R.A. ; Sousa, S.H.M. 2007. Sedimentary changes on the southeastern Brazilian Upper Slope during the last 35,000 years. Anais da Acad. Brás. de Ci., v. 79, p. 171-181.

Mahiques, M. M. ; Silveira, I.C.S ; Sousa, S. H. M. ; Rodrigues, M. 2002. Post-LGM Sedimentation on the outer shelf / upper slope in the northernmost part of the São Paulo Bight, South-Eastern Brazil. Marine Geology, Amsterdam, v. 181, n. 4, p. 387400, 2002.
O'callaghan, J. F. \& D. M. Mark, D.M.1984. The extraction of drainage networks from digital elevation data, Comput. Vision and Image Processing, 28, 323.

Pike, R.J. 1988: The geometric signature: quantifying landslide-terrain types from digital elevation models. Mathematical Geology 20, 491-511.

Popescu I., Lericolais G., Panin N., Wong H.K., Droz L. 2001. Late Quaternary channel avulsions on the Danube deep-sea fan, Black Sea. Marine Geology, 179(12): $25-37$

Steinke, S., Kienast, M. \& Hanebuth, T. 2003., On the significance of sea-level variations and shelf paleomorphology in governing sedimentation in the southern South China Sea during the last deglaciation, Mar. Geol., 201, 179 - 206.

Wescott, W.A., 1993. Geomorphic thresholds and complex response of fluvial systems-some implications for sequence stratigraphy. Am. Assoc. Pet. Geol. Bull. 77 7, pp. 1208-1218.

Winguth C., Wong H.K., Panin N., Dinu C., Georgescu P., Ungureanu G., Krugliakov V.V., Podshuveit V., 2000. Upper Quaternary sea level history and sedimentation in the northwestern Black Sea. Marine Geology, 167(1-2): 127-146. 